\title{
Entre práticas e críticas: Michel Foucault, os feminismos e o sujeito
} Between Practices and Criticisms: Michel Foucault, Feminisms and The Subject

Eloisa Rosalen

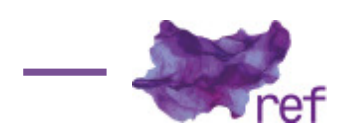

MCLAREN, Margaret A.

Foucault, Feminismo e Subjetividade.

Trad. de Newtow Milanez. São Paulo: Intermeios, 2016.

\begin{abstract}
As produções do filósofo Michel Foucault desenvolveram-se no mesmo período em que vimos a emergência de novos feminismos e de movimentos de resistências à ordem na França. Mas quais foram as contribuições que esse autor deixou aos feminismos? Que apropriações/críticas têm sido feitas sobre as teorias de Foucault pelas feministas? Ou ainda, por que as feministas devem - ou deveriam - apropriar-se das teorias (principalmente, relações de poder, sujeito e subjetividade) desse filósofo? Foram essas perguntas que a também filósofa Margaret $A$. McLaren buscou responder, por meio das diferentes leituras de teóricas feministas dos Estados Unidos, no livro Foucault, Feminismo e Subjetividade. São, entre teorias, práticas e críticas ou entre os feminismos, o sujeito, e as obras de Michel Foucault a finalidade deste livro.

Margaret A. McLaren é formada em filosofia pela Miami University (1982), com mestrado em artes pela Northwestern University (1988) e doutorado pela mesma universidade (1991) sob orientação de Nancy Fraser. Atualmente, é professora de filosofia e coordenadora do Programa de Sexualidade, Gênero e Estudos da Mulher na Rollings College. As áreas de pesquisa da autora têm como foco a teoria feminista, a filosofia francesa do século XX, a ética, a filosofia social e política, e os direitos humanos e globalização. Acerca do feminismo, além do livro aqui resenhado, organizou Decolonizing Feminism: Transnational Feminism \& Globalization (2017). A única obra que pode ser encontrada traduzida para o português é a aqui resenhada.

Dentro dos estudos de gênero, feminismos ou subjetividades, todas sabem de um modo geral quem foi Michel Foucault. Apesar de difícil definir em breves palavras sua vasta publicação, cabe situar com algumas informações. Paul-Michel Foucault nasceu, viveu e desenvolveu a maior parte de sua trajetória de pesquisa na França (Didier ERIBON, 1990). Constituiu os seus estudos, principalmente, nas grandes áreas da filosofia, da psiquiatria e da história. Foi um dos mais importantes filósofos do século XX ao formular e reformular uma série de temas, como: relações de poder, disciplina, vigilância, história da emergência da clínica, da sexualidade, da loucura/do louco. Além disso, desenvolveu pesquisas que envolveram a maneira como se deu a constituição das ciências modernas, apresentou a dinâmica complexa existente entre saber e poder, e, de um modo geral, deixou importantes reflexões sobre as instituições disciplinadoras. Seu foco pode ser pensando em três objetos principais: o saber, o poder e o sujeito.

Conforme bem lembrado pela autora no primeiro capítulo de sua obra, e anunciado por Foucault no ano de 1982 em O Sujeito e o Poder, o que ele buscou estudar ao longo de sua vida
\end{abstract}


foi a história das diferentes maneiras como os seres humanos se tornam sujeitos (Michel FOUCAULT, 1995, p. 274), isto é, quais foram as práticas sociais, instituições, relações de poder, discursos e técnicas de si que os constituem. Logo, o objeto principal das suas pesquisas não é o poder/saber - como muitas pessoas tendem a pensar - mas o sujeito (FOUCAULT, 1995, p. 274) e as circunstâncias históricas que fizeram o seu nascimento. De um modo geral, pensar sujeitos significa pensar os processos de subjetivação ou práticas de objetivação (como pode ser visto em As palavras e as coisas), as "práticas divisórias" (através, por exemplo, do "louco" e do "são" em História da Loucura) e as subjetividades (vistas principalmente na fase ética de Foucault, a partir das técnicas de si em História da Sexualidade, volumes II e III) (FOUCAULT, 1995, p. 273-274). Tais questões, como a constituição dos sujeitos, entrelaçadas ao corpo, ação política feminista e subjetividades foram os objetos principais de Foucault, Feminismo e Subjetividade.

Nesse sentido, no primeiro capítulo, "O feminismo e o debate sobre Foucault: Apostas, Questões, Posições", a autora apresenta de maneira introdutória as tensões/disputas entre os feminismos e suas posições (críticas ou não) com relação a Michel Foucault. De modo geral, é sinalizado sobre os diferentes feminismos (como: radical, marxista, socialista, teoria crítica feminista, multicultural, global e pós-moderno) e as noções básicas de discordâncias e afinidades de cada grupo com relação à utilização das produções do autor. Nessa introdução, Margaret A. McLaren também apresenta que sua posição é de aproximação direta com o autor e que a partir de alguns eixos (como as técnicas de si) sinalizará como as teorias do filósofo podem ser aplicadas pelas feministas contemporâneas.

No segundo capítulo, "Foucault, Feminismos e Normas", a autora aborda as críticas a Michel Foucault com relação à ausência de fundamento político emancipatório ou libertário em suas obras. É inquestionável que, diferentemente dos pensadores/filósofos dos séculos XVIII e XIX, Foucault não ofereceu uma leitura macro de transformação social/ação política ou ainda um engajamento profético de revolução. No entanto, discordando de muitas leituras acerca do autor, McLaren considera que as noções normativas retrabalhadas por Foucault podem oferecer fundamentos significativos para as políticas feministas (Margaret A. MCLAREN, 2016, p. 38). Assim, ao abordar as diferentes críticas provenientes de diferentes posições feministas, considerou que o método genealógico tem uma função social crítica e que a noção de relações de poder/resistências e de sujeito constituído a partir das normas sociais (historicamente construídas) são eixos desenvolvidos por Foucault, que as feministas devem incluir em seus debates.

É explícito que a concepção de sujeito (e consequentemente de subjetividade) de Michel Foucault rompe com o sujeito cartesiano, liberal ou humanista, ainda presente no momento de suas produções. Apesar de não ser uma concepção homogênea, a perspectiva foucaultiana de sujeito têm aproximações com os vários movimentos feministas. Nesse sentido, no terceiro capítulo, "Foucault e o Sujeito do Feminismo", Margaret A. McLaren trata de maneira mais aprofundada as críticas feministas com relação ao sujeito e às subjetividades de Michel Foucault. De acordo com a pesquisadora, as acusações a Foucault são de que aboliu totalmente a subjetividade e que propõem um sujeito totalmente determinado (MCLAREN, 2016, p. 76). A autora responde a tais críticas ao demonstrar que o poder também é produtivo, que as relações entre disciplina, poder, discursos e subjetividades são extremamente complexas e que se pautar somente nas obras genealógicas não faz justiça à concepção de sujeito e subjetividade de Foucault, sobretudo, porque as desenvolveu nos volumes II e III de História da Sexualidade, (REVEL, 2011; FOUCAULT, 1984a; FOUCAULT, 1984b). Nesse capítulo, fica ainda mais contundente, por meio das sugestões da autora, o entendimento de que o poder (ou as relações de poder) deve ser incorporado pelos diferentes feminismos para uma maior compressão de si, das hierarquias, das diversidades e das diferentes formas de resistências.

Tratar de sujeitos e subjetividades significa falar de seus corpos - foco do capítulo seguinte: "Foucault e o Corpo: Uma Reavaliação Feminista". Segundo a autora, tanto para Foucault quanto para as feministas, o corpo é central para o pensamento da subjetividade, uma vez que as ideias corporais são parte do aparato normativo que molda nossas vidas (MCLAREN, 2016, p. 130). Apesar das aproximações, a autora traz as críticas de Judith Butler com relação à ideia de corpo de Foucault. Da mesma forma, apresenta críticas de outras feministas que dizem ser Foucault androcêntrico (tanto por sua desatenção ao gênero/sexo quanto por seu foco no masculino), possuir uma visão de corpo natural ou pré-discursivo e que sua noção de corpo é completamente determinada pelas forças sociais. Apesar de considerar válidas algumas dessas críticas, principalmente no que tange ao androcentrismo, a resposta que McLaren oferece é que as noções de corpo de Foucault e das feministas devem caminhar juntas, uma vez que se complementariam.

Além do corpo, falar de sujeitos também significa pensar identidades ou práticas políticas feministas que envolvam identidades, como proposto no quinto capítulo, "Políticas de identidade: Sexo, gênero e sexualidade". Para McLaren, apesar de muitas feministas considerarem perigoso o uso da identidade como categoria políica, não existe um acordo no que tange a seu emprego; o que se configura é uma série de disputas, tanto entre as feministas quanto entre os grupos que se 
baseiam em construções identitárias, como gays, lésbicas etc. Também, ao exemplificar com as situações das pessoas intersexuais' ${ }^{1}$ e bissexuais, a autora enfraquece a noção de identidades estáveis e complexifica o debate acerca das categorias sexo, gênero e sexualidade e as dinâmicas que envolvem binarismos e heterossexualidade compulsória. Nesse sentido, para a autora, as obras de Foucault, com suas concepções de genealogia, poder, saber e identidade (adicionada aqui por mim), fornecem ferramentas à crítica social e consequentemente à transformação.

A noção de transformação é a que Margaret A. McLaren dá como desfecho, como pode ser visto no último capítulo denominado "Práticas de si: da transformação de si à transformação social". Nessa parte, o foco é a técnica de si, a partir, principalmente, das escritas de si e a prática de falar a verdade, desenvolvida por Michel Foucault tanto em Uso dos Prazeres e O Cuidado de Si quanto em outros textos e entrevistas do autor publicados nos Estados Unidos. As práticas de si de Foucault são vistas pela pesquisadora como um mecanismo para a transformação social. Nesse sentido, a partir do exemplo dos grupos de consciências ${ }^{2}$ feministas emergentes nos Estados Unidos durante os anos de 1960, a autora sugere que as transformações de si - como ocorreram em tais grupos - são um importante passo em direção à transformação política. De um modo geral, McLaren aponta a partir das concepções de Foucault, no tocante às técnicas de si e às relações de poder, uma leitura alternativa que vise a transformação, diferente daquelas que o apresentou como determinista e sem um projeto de transformação. Aqui se vê o entrelaçamento direto entre os feminismos emergentes (e suas práticas) dos anos de 1960 e 1970 com os estudos (e teorias) de Michel Foucault.

Ao longo do livro, a autora situa as obras de Foucault e quais sãos as suas contribuições para os feminismos, especialmente, no que diz respeito à perspectiva analítica do poder/relações de poder, às normas sociais, às críticas ao sujeito moderno e sua concepção de sujeito e subjetividades. Na minha análise, além da desnaturalização de categorias, como mulher/mulheres e corpo natural sugeridas pela autora, tal perspectiva analítica contribui tanto para uma leitura das dinâmicas sociais quanto para uma autoanálise dos feminismos e suas disputas. Da mesma forma, McLaren também assinala as diferentes críticas provenientes das feministas ao autor, principalmente, no que tange às subjetividades, à noção de poder e ao androcentrismo. Apesar de uma escrita coesa e de os argumentos estarem bem conectados, para uma melhor compreensão indico a necessidade de leituras prévias das principais obras de Michel Foucault, como a História da Sexualidade I, II e III e Microfísica do Poder, com suas noções básicas de poder, sujeito, genealogia e técnicas de si.

O livro Foucault, Feminismo e Subjetividade é um material indispensável para entender as diferentes relações (apropriações, críticas e debates) entre os movimentos feministas/teóricas feministas norte-americanas e as pesquisas realizadas por Michel Foucault. Assim, tal material se constitui como uma importante fonte teórica para os nossos estudos. A interlocução da obra é com as diferentes posições feministas, como Judith Butler, Susan Bordo, Nancy Hartsock, Nancy Fraser, entre outras feministas norte-americanas que a autora nos presenteia como sugestões de leituras. Nesse sentido, a leitura e análise da autora limitam-se, em sua grande maioria, ao exame de feministas do Norte Global, o que deixa em aberto várias perguntas: como as feministas do Sul Global (incluindo o Brasil) estão se apropriando de Michel Foucault? As perspectivas e críticas feministas centradas na Europa e nos Estudos Unidos possuem a mesma dimensão para o restante do mundo ou são válidas para as nossas realidades? De certa maneira, esses questionamentos indicam ausência de um maior diálogo com os feminismos des/pós-coloniais e causam certo desconforto sobre a utilidade do debate teórico/prático provenientes de Michel Foucault e das feministas norte-americanas (propostos no livro) com relação às atuais demandas dos feminismos latino-americanos.

\section{Referências}

ERIBON, Didier. Michel Foucault 1926-1984. Trad. de Hildegard Feist. São Paulo: Companhia das Letras, 1990.

FOUCAULT, Michel. "O sujeito e o poder". In: RABINOW, Paul; DREYFUS, Hubert Lederer (Eds.). Michel Foucault, uma trajetória filosófica: para além do estruturalismo e da hermenêutica. Trad. de Vera Porto Carrero. Rio de Janeiro: Forense Universitária, 1995. p. 273-295.

\footnotetext{
' Apesar de na atualidade o termo corrente utilizado para designar a variação de caracteres sexuais (como cromossomos, gônadas e/ou órgãos genitais) ser o de intersexo, na maior parte do capítulo o vocábulo empregado foi hermafrodita. Tal situação decorre pela utilização direta do termo ao se referenciar aos escritos de Michel Foucault, uma vez que a autora sinaliza reconhecer a denominação atual (MCLAREN, 2016, p. 167).

${ }^{2}$ Conforme Joana Maria Pedro e Cristina Scheibe Wolff (2007), os grupos de consciência emergiram a partir dos meados dos anos 70, nos Estados Unidos, onde mulheres (muitas donas de casa de classe média urbana) passaram a discutir sobre as suas próprias vidas. A formação de grupos de consciência aconteceu em diversos países, inclusive no Brasil pós-ditadura e entre as mulheres exiladas durante a ditadura como o grupo Nosotras e o Círculo de Mulheres Brasileiras em Paris. Conforme: PEDRO, Joana Maria; WOLFF, Cristina Scheibe. "Nosotras e o Círculo de Mulheres Brasileiras: feminismo tropical em Paris". Revista ArtCultura, v. 9, n. 14, p. 55-69, 2007.
} 
FOUCAULT, Michel. História da Sexualidade 2: O uso dos prazeres. 13. ed. Trad. de Maria Thereza da Costa Albuquerque. Rio de Janeiro: Edições Graal, 1984a.

FOUCAULT, Michel. História da Sexualidade 3: O cuidado de Si. 12. ed. Trad. de Maria Thereza da Costa Albuquerque. Rio de Janeiro: Edições Graal, 1984b.

REVEL, Judith. Dicionário Foucault. Trad. de Anderson Alexandre da Silva. Rio de Janeiro: Forense Universitária, 2011.

Eloisa Rosalen (iD 0000-0001-5125-9969

Doutoranda em História pela Universidade Federal de Santa Catarina

Possui graduação (2011) e mestrado em História (2016) pela Universidade Federal de Santa Catarina. É bolsista de doutorado do Conselho Nacional de Desenvolvimento Científico e Tecnológico (CNPq) e pesquisadora do Laboratório de Estudos de Gênero e História (LEGH). Tem experiência na área de História, com ênfase em História do Brasil, atuando principalmente nos seguintes temas: exílio, relações de gênero, memórias, e ditadura militar no Brasil.

Universidade Federal de Santa Catarina, Programa de Pós-Graduação em História

R. Eng. Agrônomo Andrei Cristian Ferreira, 570 - Trindade

88040-535 - Florianópolis - SC - Brasil

+55 (48) 3721-4136 - ppghst@contato.ufsc.br

rosaleneloisa@gmail.com

\section{COMO CITAR ESSE ARTIGO DE ACORDO COM AS NORMAS DA REVISTA}

ROSALEN, Eloisa. "Entre práticas e críticas: Michel Foucault, os feminismos e o sujeito". Revista Estudos Feministas, Florianópolis, v. 27, n. 1, e56989, 2019.

CONTRIBUIÇÃO DE AUTORIA

Não se aplica

FINANCIAMENTO

Conselho Nacional de Desenvolvimento Científico e Tecnológico (CNPq)

CONSENTIMENTO DE USO DE IMAGEM

Não se aplica

APROVAÇÃO DE COMITÊ DE ÉTICA EM PESQUISA

Não se aplica

CONFLITO DE INTERESSES

Não se aplica

LICENÇA DE USO

Este artigo está licenciado sob a Licença Creative Commons CC-BY. Com essa licença você pode compartilhar, adaptar, criar para qualquer fim, desde que atribua a autoria da obra.

\section{HISTÓRICO}

Recebido em 10/05/2018

Aceito em 30/06/2018 